\title{
LIBERDADES EM CONFLITO: A IMPOSIÇÃO DE LIMITES À LIBERDADE DE ENSINO COM FUNDAMENTO EM SUPOSTAS VIOLAÇÕES DE OUTRAS LIBERDADES CONSTITUCIONAIS
}

\section{FREEDOMS IN CONFLICT: THE IMPOSITION OF LIMITS ON FREEDOM OF EDUCATION BASED ON ALLEGED VIOLATIONS OF OTHER CONSTITUTIONAL FREEDOMS}

\author{
${ }^{1}$ Artur Amaral Gomes
}

\section{RESUMO}

O direito à educação é um dos principais instrumentos delineados pela Constituição de 1988 a fim de assegurar a eficácia do seu texto, assim como o cumprimento de seus objetivos fundamentais. A união do direito à educação com o complexo constitucional de liberdades resultando no princípio da liberdade de ensino foi mais uma forma que o poder constituinte encontrou para garantir a concretização do seu plano para a sociedade brasileira. Entretanto, a liberdade de ensino tem sofrido restrições fundamentadas em supostas violações de outras liberdades constitucionais, formando assim conflitos entre direitos fundamentais. A partir do manejo do método de pesquisa bibliográfica, o presente artigo pretende demonstrar como estas supostas violações são frutos de uma interpretação distorcida do texto constitucional que busca a legitimação de comportamentos discriminatórios.

Palavras-chave: Educação, Liberdade de ensino, Direitos sociais, Direitos fundamentais

\begin{abstract}
The right to education is one of the main tools outlined by the 1988 Constitution in order to ensure the effectiveness of its text, and the fulfillment of its fundamental goals. The union of the right to education with the constitutional freedoms complex resulting in the principle of freedom of education was one more way that the constituent power found to ensure implementation of its plan for Brazilian society. However, freedom of education has suffered restrictions based on alleged violations of other constitutional freedoms, thus forming conflicts between fundamental rights. From the handling of the bibliographic search method, this article intends to demonstrate that these alleged violations are the result of a distorted interpretation of the constitutional text that seeks to legitimize discriminatory conducts.
\end{abstract}

Keywords: Education, Freedom of education, Social rights, Fundamental rights

\footnotetext{
${ }^{1}$ Mestrando em Direito Ambiental pela Universidade do Estado do Amazonas - UEA, Amazonas (Brasil). E-mail: artur_gomes92@hotmail.com
} 


\section{INTRODUÇÃO}

Batizada por muitos como Constituição cidadã ou Constituição libertária, a Constituição Federal de 1988 traz em seu bojo muitos direitos e garantias que objetivam a proteção dos interesses do cidadão, armando este com meios e fundos de modo a assegurar que todos os aspectos do seu convívio social gozem de compatibilidade com o mais benéfico dos conceitos de dignidade humana. Repleta de objetivos, mandamentos e diretrizes, a Constituição de 1988 também pode ser encarada como um guia para tempos futuros que apresentarão uma sociedade cada vez mais alinhada com aquela que salta do texto constitucional.

Regulando todas as etapas e prismas da vida de um cidadão, desde o nascimento até a morte, a Constituição almeja ser capaz de erguer uma sociedade melhor, mas construindo cidadãos melhores com a esperança de que estes realizem seu objetivo inicial. Fundamentando-se em ideais de igualdade, liberdade, justiça e solidariedade, a Constituição desenha a vida em sociedade com a esperança de que seus destinatários sejam capazes, ou melhor, estejam dispostos de viver a partir dos princípios e valores contidos em seu texto.

A fim de deixar suas vontades evidentes, ceifando o máximo possível de eventuais futuras interpretações equivocadas, a Constituição traz em seus artigos iniciais os fundamentos e os objetivos fundamentais do país para em seguida passar a enumerar direitos e garantias fundamentais, normas que, em uma eventual discussão acerca da existência ou não de hierarquia em nível constitucional, caso fossem colocadas em seu mais alto patamar, pouca desordem causariam.

Não sendo um ser literalmente vivo, não sendo capaz de desenhar seus anseios e sendo um documento que deve existir separadamente daqueles responsáveis pela sua redação e edição, a Constituição de 1988 fez o possível para assegurar que suas normas programáticas não fossem deixadas de lado ou postas em prática de forma deturpada. Para tanto, como já dito anteriormente, armou o texto constitucional com instrumentos, que quando manejados corretamente, encaminhariam a sociedade para um futuro melhor.

Não só a previsão, mas o enriquecimento do conteúdo e da regulação, em nível constitucional, de direitos sociais básicos, foi uma das formas encontradas pelo poder constituinte de expor a seriedade dos seus objetivos fundamentais, ou seja, tomando as rédeas e estabelecendo os fundamentos de direitos e prestações mínimas de alta relevância para o alcance e manutenção da dignidade da pessoa humana (fundamento da República Federativa 
do Brasil) e de uma sociedade livre, justa e solidária (objetivo fundamental da República Federativa do Brasil).

O direito à educação, presente no rol de direitos sociais do artigo $6 .^{\circ}$ da Constituição ocupa posição privilegiada como instrumento de realização dos objetivos constitucionais. Não seria por outro motivo que o poder constituinte dedicou-se a pormenorizar, em nível constitucional, aquilo que não achou certo delegar para o legislador ordinário, ou melhor, dedicou-se a limitar a liberdade do legislador ordinário a fim de evitar o surgimento, que seria e é, inevitável, de normas inconstitucionais, flagrantes ou, até mesmo, "tímidas".

Os artigos 205 a 214 da Constituição de 1988 regulamentam o direito brevemente citado no artigo $6 .^{\circ}$ e tal tarefa realizam de forma a interligar o direito à educação com os principais direitos e garantias delineados por todo o texto constitucional, muitos de caráter fundamental. Consequentemente, é evidente o vínculo que se forma entre os objetivos fundamentais dispostos no artigo $3 .^{\circ}$ e a forma como a Constituição demanda que o direito à educação seja desenvolvido.

Uma vez que a promulgação da Constituição de 1988 representou o ápice de um processo de reconstitucionalização democrática, não espanta a constatação de que o seu texto apresenta um bloco variado de direitos e garantias de liberdade, e estes também se entrelaçam com o direito à educação. O liame entre educação e liberdade encontra-se consolidado expressamente no artigo 206 da carta constitucional, artigo que em seu inciso II prevê a liberdade de ensino como um dos princípios norteadores da educação no país.

Delineadas as estratégias utilizadas pela Constituição a fim de garantir o sucesso de seus mandamentos, o presente artigo objetiva destacar o direito à educação como instrumento para tanto e a forma como sua regulamentação, no próprio texto constitucional, o conecta intrinsecamente ao complexo constitucional de liberdades, trazendo à tona supostos conflitos entre tais liberdades, sobretudo quando da discussão acerca da imposição de limites às manifestações provenientes da liberdade de ensino.

\section{EDUCAÇÃO SOB A ÓTICA DA LIBERDADE}

Componente do rol de direitos sociais previsto no art. $6 .^{\circ}$ da carta constitucional, o direito à educação encontra suas diretrizes pormenorizadas constitucionalmente nos artigos 205 a 214, onde o poder constituinte, entre outras providências, estabeleceu os princípios que 
devem guiar o ensino brasileiro. O artigo 205 estabelece os destinatários da educação enquanto direito (todos) e dever (Estado e família), clama pela contribuição da sociedade e enumera os três principais objetivos da educação brasileira: o pleno desenvolvimento da pessoa, o seu preparo para o exercício da cidadania (direitos políticos) e a sua qualificação para o trabalho.

Nos termos de José Afonso da Silva (2013, p. 315), “o art. 205 contém uma declaração fundamental que, combinada com o art. $6 .^{\circ}$, eleva a educação ao nível dos direitos fundamentais do homem". Conclui-se, portanto, que o caráter fundamental básico do direito social à educação previsto no artigo $6 .^{\circ}$ é indiscutível, contudo não é possível negar que o seu texto também o apresenta como geral, abrindo-se a discussão acerca do conteúdo dos artigos

205 a 214. Ingo Wolfgang Sarlet (2013, p. 605) enxerga tais artigos como integrantes do complexo normativo constitucional essencial do direito à educação, porém ainda expressa receio em considerá-los como dispositivos fundamentais. Entretanto, mais especificamente, quanto aos artigos 205 a 208, os quais elucidam o conteúdo e o alcance do direito à educação, ou seja, os aspectos essenciais do direito fundamental simploriamente previsto no artigo $6 .^{\circ}$, observa que a sua função no campo da eficácia do direito em análise é mais que o suficiente para evidenciar o seu caráter fundamental.

Quanto aos princípios jurídicos que regem a educação enquanto direito fundamental social, Regina Garcia de Paiva (2010, p. 72) aponta que estes possuem natureza própria e específica em razão dos próprios objetivos da educação, entre eles a formação da personalidade do homem. Neste mesmo sentido, André Trindade (2010, p. 50) afirma que o cumprimento da função social da educação só pode ser alcançado se observados os princípios que guiam a vida social e a manutenção da dignidade humana. Para o autor, o cumprimento ocorre com a formação de pessoas com uma consciência forte e que sejam capazes de "participar" de uma sociedade igualitária.

Colocando a construção da personalidade do homem como objetivo da educação, Paiva (2010, p. 71) conclui que "há, na educação, a clara preocupação de pôr o homem como o centro de todo o esforço, e todo o empreendimento será no sentido da construção da pessoa humana". Seguindo tal raciocínio, Trindade (2010, p. 44) assevera que "a educação é uma construção do homem, com o homem e para o homem", uma vez que, respectivamente, é uma característica do homem estar sempre buscando mais conhecimento; que o homem faz parte de um meio social onde o conhecimento é produzido por e entre homens; e que a reunião de conhecimentos pelo homem sempre objetiva saciar alguma necessidade humana. 
Pablo Bonilla Chaves (2010, p. 57) destaca entre as funções basilares da educação "a de dar direção, servir de norte aos imaturos, para que a sociedade não apenas persevere, mas também atinja seus ideais". Tal pensamento, que une os campos individual e social onde a educação deve agir, também resume a maneira como Paiva (2010, p. 77) enxerga a educação, como um "meio de desenvolver integralmente a personalidade humana e de possibilitar-lhe a participação na obra do bem comum. Acentua-se a necessidade de harmonia entre o aprimoramento individual e o desenvolvimento do bem comum”. Masako Shirai (2010, p. 639) acompanha tal visão, definindo educação como o "processo de desenvolvimento da capacidade física, intelectual e moral da pessoa, conduzindo-a a sua plenitude individual e social".

A partir de uma análise em conjunto com os princípios democráticos constitucionais, Chaves (2010, p. 79) conceitua um tipo ideal de educação como sendo o processo pelo qual membros imaturos de uma sociedade são modelados intelectual e moralmente pelos membros maduros, utilizando para tanto técnicas de transmissão de conhecimento, cultura e valores. Tal modelagem teria como objetivo alcançar um patamar satisfatório de desenvolvimento social, o suficiente para que os "modelados" possam desfrutar de certa ascensão social individual e, consequentemente, geral, se desenvolvidos o suficiente para ocupar espaços na gestão da máquina pública.

Eid Badr (2011, p. 61) destaca que "a transmissão do conhecimento, o ensino, serve à educação, cujo perfil e objetivos estão delineados constitucionalmente". Verifica-se, portanto, que a transmissão de informações é o núcleo do direito à educação, motivo pelo qual deve manter-se em sincronia com os demais mandamentos constitucionais, a fim de que os destinatários de tal direito sejam modelados de acordo com os valores estabelecidos constitucionalmente. Com este pensamento, Chaves (2010, p. 173) questiona a própria conceituação que apresenta de educação: “como garantir a liberdade e combater a homogeneização se a educação, em suma, envolve o emolduramento dos indivíduos aos ideais constitucionais?”. Em seguida, o autor esclarece que não existe aí um paradoxo, uma vez que a educação, segundo os preceitos constitucionais, goza de um caráter libertário que não pode ser interpretado de forma engessada. Chaves (2010, p. 205) finaliza: “a transmissão dos valores presentes e emanados da Constituição não tem possibilidade de tolher, dos indivíduos e grupos destes, as suas particularidades culturais, étnicas, enfim; identitárias".

Ainda a fim de dissipar qualquer resquício paradoxal, Chaves (2010, p. 167) defende que a "Constituição é por demais libertária e igualitária para que qualquer sentimento a ela 
ligado pudesse conduzir a discriminações negativas". Contudo, o autor também ressalva que, ao impor seus valores, a carta constitucional não ceifa a capacidade de pensar própria de cada indivíduo, e, caso o fizesse, acabaria contrariando a si mesma, ou seja, Chaves (2010, p. 174) reforça que a Constituição não defende a imposição de formas de pensar, isso fica claro com a previsão constitucional do princípio da liberdade de ensino, ou seja, a proteção e a transmissão de valores constitucionais no processo educacional não podem ser confundidas com a promoção de interesses incompatíveis com as diretrizes constitucionais.

O artigo 206 da carta constitucional, dispositivo que reúne os princípios que norteiam o ensino, traz em si normas diretamente aplicáveis, isto é, dotadas de plena eficácia, uma vez que confirmam outros direitos e princípios já previstos no texto constitucional, mas demonstrando o papel destes quando vinculados ao cumprimento do direito fundamental à educação. Ao pregar pela liberdade de ensino, o inciso II do artigo supracitado, para Sarlet (2013, p. 607), expõe uma nova face do direito à liberdade quando unido ao direito à educação e, assim, gera novos direitos subjetivos aos particulares imersos em relações educacionais. A fim de facilitar a compreensão da relação entre educação e liberdade, cabe aqui uma análise dos principais componentes do bloco constitucional de liberdades brasileiro.

\section{COMPLEXO CONSTITUCIONAL DE LIBERDADES}

Concentrando-se majoritariamente no art. $5^{\circ}$ da Constituição de 1988 , o complexo constitucional de liberdades atua em todas as áreas da vida individual e social das pessoas, tornando-se assim elemento fundamental na manutenção da dignidade humana. José Afonso da Silva (2013, p. 235) conceitua liberdade como "a possibilidade de coordenação consciente dos meios necessários à realização da felicidade pessoal". Neste artigo destacam-se as liberdades voltadas para a comunicação, ferramenta (ou meio) de alta relevância para o desenvolvimento da educação. Antes de abordar liberdades específicas, uma breve análise do chamado direito geral de liberdade é indispensável para o sucesso do presente estudo.

A Declaração dos Direitos do Homem e do Cidadão de 1789, um dos resultados da Revolução Francesa, explicita em seu artigo 4. ': "A liberdade consiste em poder fazer tudo o que não prejudica ao outro". Segundo Sarlet (2013, p. 445), tal pensamento possibilita concluir que "todo ser humano possui uma área ou esfera de liberdade pessoal que não pode ser de qualquer modo violada e na qual pode desenvolver suas faculdades e vontades naturais livres de qualquer interferência externa". Sarlet (2013, p. 445) ainda aponta que a ideia de um direito 
geral de liberdade está intimamente vinculada com a ideia de direito ao livre desenvolvimento da liberdade, sendo que ambas fundamentam-se na proteção à dignidade da pessoa humana.

Segundo Robert Alexy (2015, p. 344), um direito geral de liberdade não protege apenas o "fazer", mas também o "ser" nos campos fático e jurídico. A partir deste pensamento, o autor demonstra como as intervenções nas posições intelectuais de um indivíduo acabam alterando como tal indivíduo manifesta a sua liberdade de ação. Existe aí uma hipótese de intervenção indireta na liberdade de ação a partir de intervenções diretas no âmbito de proteção das liberdades de comunicação.

Ainda quanto ao direito geral de liberdade, Sarlet (2013, p. 446) destaca que, no ordenamento jurídico brasileiro, tal direito apresenta duas dimensões, uma positiva e outra negativa, a primeira com aspectos de ação e de exercício, e a segunda com ares de omissão e "abandono" por iniciativa própria. A partir deste pensamento, para Alexandre Assunção e Silva (2012, p. 09), "a liberdade humana pode ser voltada para a realização de qualquer fim, mesmo que considerado imoral, até porque o conceito do que é imoral é variável". No entanto, esta liberdade de dimensão positiva deveras aberta, apesar de não aparentar, é rodeada por restrições que serão abordadas no próximo item, assim como as problemáticas advindas destas.

No que tange às liberdades vinculadas a personalidade do homem, a figura da consciência humana, sobretudo a individual, é de fundamental importância, funcionando como guia do exercício de todas as liberdades. Primeiramente, é importante salientar que liberdade de consciência e liberdade religiosa, apesar de vinculadas, não se confundem. A primeira possui uma abrangência bem mais ampla, sendo verdadeira faculdade ou convicção pessoal que não possui relação direta com mandamentos ou diretrizes religiosas. A segunda, independentemente, indica a liberdade de "ter" ou não uma religião, ao passo que são os desdobramentos de tal "decisão" que costumam gerar conflitos entre liberdades. Obedecer a um mandamento religioso é diferente de agir com o intuito de expor uma convicção pessoal em nada vinculada com qualquer religião. Trata-se de uma linha tênue que para muitos, não exatamente doutrinadores, mas "militantes", não existe, o que dá origem a confusão entre os termos.

Jayme Weingartner Neto (2013, p. 268) identifica a autodeterminação ético- existencial como o bem fundamental protegido pela liberdade de consciência, abrangendo desde a liberdade para construir convicções próprias até a exteriorização de "decisões de consciência". Resumindo, reúne todas as consequências da liberdade de agir, ou deixar de agir, sempre 
segundo uma consciência personalíssima. Para Gilmar Mendes e Paulo Branco (2014, p. 318), o reconhecimento constitucional da liberdade religiosa significa que o sistema jurídico atual enxerga a religião também como um bem, como um valor a ser conservado e estimulado, da mesma forma como funciona com a consciência geral, isto é, livre de caráter religioso.

Quanto ao papel do Estado diante da liberdade de consciência, Mendes e Branco (2014, p. 312) afirmam que perfaz dever do Estado o de proporcionar meios de formação autônoma da consciência. Consequentemente, deve o Estado admitir que aquele indivíduo, o qual ajudou a formar sua consciência, se comporte no âmbito social em conformidade com suas convicções. Trata-se da liberdade de manifestação concreta da consciência.

Importante tratar ainda sobre a chamada objeção de consciência. Segundo Mendes e Branco (2014, p. 313) tal objeção ocorre com a recusa em se comportar de uma forma prescrita, ou seja, a negativa de se submeter a um comportamento "programado" em razão de convicções próprias formadoras do caráter e da personalidade daquele que exerce tal negativa. Para José Afonso da Silva (2013, p. 244), a escusa ou imperativo de consciência consiste no direito de se recusar a agir conforme imposições que esbarram em convicções próprias do indivíduo, sejam elas de caráter religioso ou filosófico. A admissibilidade de tal objeção é a melhor forma do Estado demonstrar que respeita a consciência que supostamente ajudou a construir. Contudo o respeito exercido pelo Estado não pode se transformar em impotência, nem mesmo fadar ao fracasso objetivos e normas constitucionais.

Seguindo em frente, Sarlet (2013, p. 453) evidencia uma terminologia plural utilizada pela Constituição de 1988 ao tratar sobre livre manifestação de pensamento e liberdade de expressão. Apesar disso, não deixa de recomendar que o estudo da liberdade de expressão e de todas as demais liberdades a esta vinculadas deva ser realizado de maneira conjunta, tratase de um "complexo de liberdades comunicativas", um bloco que reúne variadas liberdades espalhadas pela carta constitucional, mas que devem ser analisadas conjuntamente, desde que respeitadas suas particularidades. O supracitado bloco aglutina a liberdade de expressão (gênero) e todas as liberdades em espécie que têm nesta o seu fundamento, entre elas a liberdade de ensino, a liberdade de manifestação do pensamento, a liberdade de comunicação e de informação e a liberdade de expressão religiosa, esta última também fundamentada nas liberdades de consciência, crença e culto (outros gêneros de liberdade).

Para Daniel Sarmento (2013, p. 255), a liberdade de expressão é "um direito que visa a proteger não apenas aos interesses do emissor das manifestações, como também aos da sua audiência e da sociedade em geral". Quanto ao conteúdo da liberdade de expressão, Mendes e 
Branco (2014, p. 264) incluem na sua órbita de proteção "toda opinião, convicção, comentário, avaliação ou julgamento sobre qualquer assunto ou sobre qualquer pessoa, envolvendo tema de interesse público, ou não, de importância e de valor, ou não", sem deixar de ressalvar as hipóteses que caracterizem colisões com outros direitos fundamentais ou valores constitucionais.

Tratando sobre o direito à liberdade de expressão, Mendes e Branco (2014, p. 264) afirmam que a formação de uma personalidade só se dá de forma plena a partir de meios que permitam conhecer a realidade e suas diversas interpretações, possibilitando assim a participação em debates e a tomada de decisões importantes, isto é, a liberdade de expressão é instrumento de alta relevância na manutenção da dignidade humana, este é o argumento humanista que fundamenta a proteção de tal direito. Outro fundamento, o democrático, enaltece a liberdade de expressão como meio de preservação do sistema democrático, uma vez que o pluralismo de opiniões é a base de qualquer democracia. A sociabilidade do ser humano é uma qualidade que, para existir, depende do direito de livre comunicação. Mendes e Branco (2014, p. 264) finalizam: "O ser humano se forma no contato com o seu semelhante, mostrando-se a liberdade de se comunicar como condição relevante para a própria rigidez psicossocial da pessoa".

A forma como Mendes e Branco abordam a liberdade de expressão facilita identificar como foi feita a vinculação constitucional entre as variadas formas de liberdade, sobretudo a de expressão, com o direito à educação, resultando no princípio da liberdade de ensino como um dos guias da educação no país. Para José Afonso da Silva (2013, p. 235), "na medida em que se desenvolve o conhecimento, se fornecem informações ao povo, mais se amplia a sua liberdade", isto é, com mais conhecimento, mais capaz se torna o homem no manejo dos meios que levam à expansão da sua personalidade. A ligação entre a liberdade de expressão e a liberdade de ensino é classificada por Sarlet (2013, p. 452) como "direta", isto é, ambas foram formuladas com a finalidade de garantir expressamente direitos de liberdade da pessoa humana.

Prevista no inciso II do artigo 206 como um dos princípios norteadores do ensino no país, a liberdade de ensino pode ser encarada a partir de mais de uma dimensão. Para Elias de Oliveira Motta (1997, p. 172), a liberdade de ensino como princípio constitucional deixa claro que "os elaboradores da Constituição garantiram sua consequência lógica, a autonomia das escolas e dos professores (liberdade de cátedra) e a livre atuação na área educacional para as instituições privadas”. Conforme assevera Badr (2011, p. 63), o princípio da liberdade de ensino 
não equivale à liberdade acadêmica, uma vez que possui sentido bem mais amplo, vinculandose a variados outros princípios constitucionais, todos componentes de um complexo de liberdades formado com o objetivo de fortalecer o Estado democrático de direito a partir de um sistema educacional que encontra em tal princípio a sua "fonte-matriz".

É comum que princípios constitucionais apresentem mais de uma dimensão de aplicação, o princípio da liberdade de ensino não foge à regra. No presente artigo, destaca-se a sua dimensão didática, aquela que trata do conteúdo do ensino. Nesta seara, segundo Paiva (2010, p. 80), a liberdade de ensino consiste na liberdade intelectual daqueles que participam do processo educacional e sua relevância se mostra em sua contribuição para o desenvolvimento do espírito crítico, para a evolução do conhecimento e para a melhoria da convivência em sociedade. Badr (2011, p. 65) ainda aponta que a liberdade didática deve ser exercida de modo a assegurar a pluralidade de doutrinas e métodos da atualidade, em compatibilidade com o princípio do pluralismo previsto no inciso III do artigo 206.

Marcelo Novelino (2012, p. 1071) confirma a direta ligação entre os princípios da liberdade de ensino e do pluralismo, destacando que cabe a este último assegurar a diversidade ideológica e pedagógica nas entidades de ensino, públicas ou privadas. Para Chaves (2010, p. 175), “a combinação ou análise combinada dos incisos II e III originam aquilo que se convencionou denominar de liberdade de cátedra”. Chaves (2010, p. 185) ainda afirma que a liberdade na educação funciona como uma característica e um objetivo concomitantemente, uma dinâmica que encontra no princípio do pluralismo a sua principal fonte de manutenção e só existindo quando combinada com tal princípio.

Mais especificamente acerca do princípio do pluralismo de ideias e de concepções pedagógicas, verifica-se que este complementa o princípio da liberdade de ensino, uma vez que ambos pregam pelo respeito à diversidade de pensamento. Marcos Augusto Maliska (2013, p. 1967) enumera diversos aspectos que envolvem tal princípio e que encontram fundamento por todo o texto constitucional, entre eles: a) reconhecimento das diferenças regionais e sociais; b) garantias do ensino religioso facultativo; c) garantia do ensino das línguas indígenas maternas no ensino fundamental; e d) ensino da História do Brasil a partir da análise de contribuições advindas de variadas culturas e etnias, sejam elas de matriz indígena, africana ou europeia, todas com o seu papel na formação da cultura e do povo brasileiro.

José Afonso da Silva (2014, p. 803) observa que a previsão constitucional do princípio do pluralismo apenas confirma a posição adotada pela Constituição de 1988 de abraçar a ideia de uma sociedade pluralista, ou seja, uma sociedade em constante conflito e repleta de 
interesses contraditórios. A união da liberdade de ensino com o pluralismo visa contribuir com a construção de um equilíbrio entre tensões sociais múltiplas, a fim de conciliar o particularismo com o espírito social.

Paiva (2010, p. 81) afirma que "o conhecimento da realidade é também condição necessária à educação porque gera participação, criatividade e senso crítico, compreensão do aluno e da sua cultura, das dificuldades internas e externas para a ação". No mesmo caminho, a partir da obra de Edgar Morin, Chaves (2010, p. 179) defende que "o cidadão local, com uma visão estreita e limitada de mundo, deve ser, através da educação, transformado em um cidadão do mundo, com uma ampliação de horizontes de mesmo calibre". Tal objetivo só pode ser alcançado a partir do exercício do princípio da liberdade de ensino cumulado com o princípio do pluralismo.

Para José Afonso da Silva (2013, p. 258), os princípios dispostos nos incisos II e III do artigo 206 reconhecem a liberdade própria da classe de profissionais que trabalham com a transmissão do conhecimento, os professores, mas também reconhecem a sua outra face, a de aprender, englobando assim todo o processo de transmissão de conhecimento e os seus atores, motivo pelo qual é denominada pelo autor como liberdade de transmissão e recepção de conhecimento. Silva (2013, p. 258) ainda destaca que tal liberdade navega por duas dimensões do "conhecer": a) o conhecer subjetivo: liberdade de transmitir o conhecimento e de recebê-lo; e b) o conhecer objetivo: liberdade que o professor tem para escolher o objeto de ensino a ser transmitido. Esta última dimensão deve obedecer aos currículos escolares, assim como ao princípio do pluralismo.

Conforme já destacado, Chaves (2010, p. 145) enxerga os princípios norteadores da educação previstos nos incisos II e III do artigo 206 da Constituição de 1988 como os principais instrumentos para o cumprimento da meta educacional de transmissão de valores constitucionais. Chaves (2010, p. 164) ainda alega que "é nítido que se a Constituição é destinada a todos, nada mais adequado do que transportá-la, nessa exata medida, ao ambiente escolar ou a qualquer outro ambiente no qual o processo educativo se faça presente".

Delineados os principais aspectos do complexo constitucional de liberdades, com ênfase nas liberdades de comunicação e naquelas voltadas para o direito à educação, fica claro que, ao serem analisadas separadamente ou somente destacando o que elas têm em comum, é difícil imaginar que na prática o exercício destas liberdades simultaneamente acaba gerando conflitos marcados pela tentativa de imposição de limites com base na defesa do exercício destas mesmas liberdades. Os pressupostos para a imposição de restrições no âmbito de proteção das 
liberdades, assim como os efeitos e requisitos para a resolução dos conflitos entre direitos fundamentais formam o núcleo do próximo item deste artigo.

\section{LIMITES E CONFLITOS ENTRE LIBERDADES}

É indubitável, segundo Pedro Lenza (2014, p. 1083), que os direitos fundamentais à liberdade não gozam de caráter absoluto. Para que um direito fundamental prevaleça em uma situação de conflito com outro, é preciso uma ponderação prévia e minuciosa, e desde que incabível a harmonização entre os direitos. Flavia Bahia (2013, p. 133) também ressalta "que as liberdades públicas não são incondicionais, absolutas, por isso devem ser exercidas de maneira harmônica, observados os limites definidos na própria Constituição". Esta espécie de restrição a direito fundamental que se faz presente no próprio texto constitucional, sendo também direito fundamental ou não, ou seja, bastando que goze de hierarquia constitucional, é denominada por Alexy (2015, p. 286) como restrição diretamente constitucional.

Segundo Marcelo Schenk Duque (2014, p. 308), “quando se fala em restrição a um direito fundamental, fala-se em uma intervenção no seu âmbito de proteção”. Observa-se, portanto, que a violação de um direito fundamental ocorre quando o seu âmbito de proteção é lesionado de forma a prejudicar o seu exercício pelo titular. Em outro giro, Duque (2014, p. 343) aponta que "a esfera de liberdade individual do particular carece de delimitação, intermediação e compatibilização recíprocas por meio do direito", o que torna legítima a existência de restrições com fins de harmonização.

Tratando especificamente sobre a liberdade de expressão, matriz das liberdades de caráter comunicativo, seu âmbito de proteção engloba inúmeras formas de manifestação, desde a manifestação de opiniões, verbais ou artísticas, até de juízos de valoração. Contudo, segundo Sarlet (2013, p. 456), tal proteção acaba se tornando discutível em algumas situações polêmicas, como na negação de fatos históricos e amplamente comprovados, no completo descumprimento com o dever da verdade fatídica e nos delitos de opinião, estes últimos se perfazendo em manifestações que violam a ordem constitucional e legal, muitas vezes constituindo conflitos entre direitos fundamentais.

Duque (2014, p. 211) afirma que uma colisão de direitos fundamentais se dá quando a vigência de um direito fundamental é privilegiada acima da de outro, ou seja, quando a concretização de um direito fundamental por um titular acaba ceifando a concretização do mesmo ou diverso direito fundamental por outro titular, ou pelo menos gerando a 
possibilidade para tanto. A fim de compreender uma colisão entre direitos fundamentais, assim como definir se existe uma colisão de fato, Duque (2014, p. 227) determina que deve ser feita a delimitação do âmbito de proteção dos direitos fundamentais envolvidos.

Quando do conflito entre direitos fundamentais, é comum que a liberdade de expressão assuma uma posição preferencial, uma vez que é considerada peça fundamental na manutenção da democracia e do pluralismo político. Entretanto, para Sarlet (2013, p. 469), trata-se de uma posição não absoluta, ou seja, não afasta a aplicação do princípio da proporcionalidade e de outros critérios quando da tentativa de resolução do conflito, evitando assim a consolidação de uma espécie de hierarquização nada razoável de normas constitucionais.

Carlos Roberto Siqueira Castro (2010, p. 72) condena a utilização de técnicas de hierarquização como forma de solução de conflitos entre normas e valores constitucionais. Para o autor, tais técnicas servem como atalho para o "radicalismo das exclusões", uma vez que é difícil existir qualquer flexibilidade em relações hierárquicas. No entanto, o autor ressalva que, no campo da hierarquia, só não existe discussão quando se admite que a vida e a dignidade humana devem ocupar posições de superioridade quando "atacadas" por outros direitos. Mesmo assim, este gesto de paz em nada ajuda na resolução de um conflito entre liberdades onde as partes opostas reclamam que o âmbito de suas liberdades ao ser invadido viola a manutenção da sua dignidade humana.

Para Castro (2010, p. 67), situações eventuais de conflito entre direitos e valores fundamentais ocorrem com maior frequência a partir do momento que liberdades ganham maior complexidade e mais núcleos de essência. O vínculo criado entre o direito à educação e o direito geral de liberdade faz justamente isso, acrescenta, ou pelo menos torna mais claro, mais um âmbito de proteção à liberdade.

Sarlet (2013, p. 470) enumera alguns pressupostos necessários ao reconhecimento de limites e à imposição de restrições à liberdade de expressão e suas demais companheiras de bloco, são eles: a) devem possuir caráter excepcional; b) devem ser promovidas a partir de lei ou decisão judicial; c) devem objetivar a proteção da dignidade da pessoa humana e de outros bens jurídico-constitucionais, conforme o caso concreto demandar; e d) devem observar critérios de proporcionalidade e de preservação do núcleo essencial dos direitos em conflito. Se realizado um procedimento que observe todos os pressupostos supracitados e ainda assim remanescer dúvida quanto à imposição ou não da restrição, entra em cena a chamada posição preferencial da liberdade de expressão, razão pela qual esta deve ser privilegiada no conflito. 
A liberdade de expressão, segundo Mendes e Branco (2014, p. 271), “poderá sofrer recuo quando o seu conteúdo puser em risco uma educação democrática, livre de ódios preconceituosos e fundada no superior valor intrínseco de todo ser humano”. Já adentrando o âmbito específico da liberdade de ensino, Badr (2011, p. 152) lembra que a criação de regras, a propagação de ideias ou de documentos de caráter discriminatório por instituições de ensino e seus componentes são condutas vedadas constitucionalmente.

Mendes e Branco (2014, p. 273) ainda afirmam que "quando se busca situar uma hipótese no domínio normativo da garantia constitucional da liberdade de expressão, há de se atentar, igualmente, para o contexto em que o discurso é proferido". Para Duque (2014, p. 383), "somente a análise do ambiente no qual está contido um direito fundamental é que poderá levar em conta quais restrições, no caso concreto, mostram-se admissíveis e quais não". Lembrando que a análise do contexto ou ambiente deve se dar tanto na hipótese de proteger um discurso quando na hipótese de tentar calar tal discurso. No contexto ou ambiente educacional, a tentativa ou a concreta restrição da liberdade de ensino pelas liberdades de consciência e de expressão trazem um novo viés a ser estudado, o do conflito entre liberdades intimamente vinculadas e que, de certo modo, decorrem uma das outras.

Apesar do nome, a liberdade de ensino não é absoluta e tem de suportar limites instrumentais e materiais. A primeira espécie diz respeito a mecanismos de avaliação e fiscalização que existem para garantir que as instituições de ensino cumpram com a sua parcela de responsabilidade advinda das diretrizes educacionais constitucionais. A segunda espécie diz respeito ao conteúdo do ensino e a sua compatibilidade com os valores e princípios do texto constitucional. Interessa aqui tratar dos limites materiais à liberdade de ensino e como tais limites podem fazer parte de um mesmo complexo de prerrogativas que quando exercidas ao mesmo tempo acabam gerando conflitos entre normas, que permanecendo ao mesmo patamar hierárquico, os tornam mais difíceis de solucionar.

Para Duque (2014, p. 312), "não se pode fechar os olhos para o fato de que as liberdades fundamentais não estão imunes a ocorrência de colisões". O autor explica tal pensamento ao afirmar que uma liberdade ilimitada do indivíduo transformaria a Constituição em um documento dispensável. A preservação da ordem constitucional depende de uma liberdade limitada de desenvolvimento dos particulares, a fim de garantir que os direitos de terceiros sejam sempre respeitados, assegurando também a busca pelo bem comum. Ainda segundo Duque (2014, p. 337), "não haveria sentido a Constituição dispor de uma série de normas de caráter fundamental, caso não estivesse preocupada com a sua própria preservação como um todo". 
Duque (2014, p. 337) também inclui a observância dos bons costumes entre os parâmetros que devem ser levados em consideração quando da imposição de restrições a direitos fundamentais, juntamente com a proteção do direito de terceiros, dos bens coletivos e da ordem constitucional.

Castro (2010, p. 64) observa que o exercício simultâneo de liberdades fundamentais por variados sujeitos de direito pode gerar conflitos aparentes de normas constitucionais, mas também aponta que estes podem ser solucionados a partir da definição da essência e dos limites de cada liberdade dentro do campo individual de cada sujeito envolvido na situação de conflito. Para Castro (2010, p. 65), "a ordem constitucional não se limita, pois, a reconhecer e garantir o valor da liberdade: associa-o ao princípio (que lhe é ínsito) da responsabilidade social e integra-o no conjunto dos demais valores comunitários". Castro (2010, p. 65) continua sua exposição explicando que as liberdades individuais possuem limites internos e externos. Os primeiros dizem respeito aos valores da dignidade humana em um nível particular e os últimos estão ligados à realização dos direitos e garantias constitucionais para a coletividade. A "conciliação" dessas espécies de limites quase sempre enseja em conflitos práticos entre valores constitucionais ou verdadeiras colisões entre direitos igualmente fundamentais.

Já mencionado anteriormente, o método de resolução de tais conflitos, segundo Castro (2010, p. 68), tem como essência a ponderação de bens, interesses, princípios e valores. Trata-se de um processo que busca medir a extensão dos direitos que buscam "primazia eficacial" em um caso concreto, de modo a encontrar um equilíbrio entre tais direitos, evitando o sucesso de um em detrimento total de outro. Castro (2010, p. 68) entende que, "enquanto método epistemológico, o procedimento exegético da ponderação de bens se revela adequado ao universo de grandezas não matemáticas que povoam o reino dos valores dentro do qual o Direito se insere". Este método de ponderação é onde se destaca a aplicação do princípio da proporcionalidade ou razoabilidade. Paulo Branco (2000, p. 183) prega que "o juízo de ponderação a ser exercido assenta-se no princípio da proporcionalidade, que exige que o sacrifício de um direito seja necessário para a solução do problema e que seja proporcional em sentido estrito", ou seja, o princípio da proporcionalidade ajuda a evitar que o sacrifício de um direito gere um ônus para outro direito maior que o benefício atingido pela preponderância do direito "vencedor", o que seria uma solução verdadeiramente injusta e prejudicial à ordem constitucional. Branco (2000, p. 183) conclui que "devem-se comprimir no menor grau possível os direitos em causa, preservando-se a sua essência, o seu núcleo essencial".

Encarando o tema por outro prisma, Duque (2014, p. 343) prega que os direitos fundamentais não foram formulados somente para satisfazer vontades individuais, mas para 
funcionar como elementos de uma ordem coletiva. A partir deste pensamento, conclui que o direito à liberdade não se traduz na faculdade de agir da forma que quiser sem se preocupar com os efeitos de tais ações para a esfera coletiva. Duque (2014, p. 343) conclui que o ponto de partida para a resolução de qualquer conflito entre direitos fundamentais é jamais enxergar o indivíduo isoladamente, mas sim imerso na coletividade, somente desta forma é possível identificar os verdadeiros âmbitos de proteção dos direitos fundamentais, assim como as suas legítimas limitações.

Também é evidente que as liberdades aqui em conflito possuem a dignidade humana como um dos seus principais fins, não faltando razão aos titulares em oposição ao clamarem que as supostas violações combatidas afetam ou afetarão a sua dignidade humana. Isto ocorre, segundo Duque (2014, p. 259), porque "a dignidade humana existe em cada pessoa como núcleo da essencialidade indedutível da natureza humana, com força no seu espírito, que lhe possibilita autodeterminação e autoconfiguração no meio em que vive".

Maliska (2013, p. 1967) denota que os limites da liberdade de ensino é um tema ligado à realidade histórica e cultural do país em que está inserido, uma vez que cada ambiente social forma elementos de consenso diferenciados e são estes elementos que criam "limites" à liberdade de ensino, excetuando-se, é claro, os casos em que princípios constitucionais são violados, como a disseminação de convicções discriminatórias por meio do ensino. Para Maliska (2013, p. 1967), o enfrentamento e a superação dos "limites" da liberdade de ensino só podem ser alcançados com a implementação de técnicas pedagógicas adequadas. A escola deve ser vista como um ambiente de aperfeiçoamento do cidadão, lugar onde o direito à diferença e ao pluralismo sejam encarados não como "limites", mas como verdadeiros objetos de discussão.

O artigo 3. ${ }^{\circ}$ da Constituição de 1988, de certa forma, apresenta os principais limites à liberdade de ensino, em sua dimensão didática, ao enumerar os objetivos fundamentais da República Federativa do Brasil. Todo conteúdo que não contribuir para o alcance de tais objetivos, acaba caracterizando verdadeira violação dos seus preceitos. Tais objetivos também funcionam como diretrizes do ensino, uma vez que a educação foi colocada como instrumento para o alcance daqueles. Em suma, os objetivos fundamentais funcionam como limites e diretrizes do ensino brasileiro e a sua concretização tem se tornado cada vez mais difícil em razão de argumentos embasados em supostas violações de liberdades cometidas no processo educacional em prol da liberdade de ensino.

Vem se tornando cada vez mais comum a imposição de restrições à liberdade de ensino, em sua dimensão didática, a partir de argumentos que objetivam proteger a liberdade de 
expressão, a liberdade de consciência e a liberdade religiosa. E, ainda, quando do exercício da liberdade de ensino juntamente com o princípio do pluralismo de ideais, surgem argumentos de que a simples exposição do que é diferente já é o suficiente para declarar a violação das liberdades antes mencionadas. Restam armados, portanto, supostos conflitos entre liberdades, originados a partir de interpretações distorcidas do texto constitucional e em completa dissonância do princípio da unidade da Constituição.

\section{CONCLUSÃO}

Explicitado o plano constitucional para a construção de uma sociedade que funciona e se desenvolve a partir de critérios de igualdade, liberdade, justiça e solidariedade, observase a existência de uma corrente de direitos, garantias e princípios alinhados com um mesmo fim ou fins. A Constituição de 1988 delimita os fundamentos norteadores de toda a República e em seguida estabelece os seus objetivos fundamentais, entre eles a promoção do bem comum e a garantia do desenvolvimento nacional. Após, a carta constitucional estabelece direitos e garantias fundamentais, destacando-se aqueles de caráter claramente social, mas todos com suas diretrizes previamente dispostas. Entre tais direitos, o presente artigo destacou o direito à educação e os direitos à liberdade de caráter comunicativo. Direitos que a Constituição tratou de unir, dando origem ao princípio da liberdade de ensino, como forma de, mais uma vez, tentar assegurar o cumprimento de seus próprios mandamentos e programas.

O caráter programático da Constituição de 1988 torna necessária a criação de tais correntes pelo poder constituinte, mas tanto esforço ainda não garante a certeza de que uma corrente como a exposta neste artigo vai conseguir atingir os seus objetivos. Como já dito anteriormente, o texto constitucional, após a sua edição, passa a existir de forma independente no ordenamento jurídico, tornando-se objeto de estudos, manipulações e interpretações pelos seus destinatários. E constitui tarefa para tais destinatários colocar essas correntes de direitos e instrumentos normativos em ação, dando-lhes eficácia no mundo social.

A corrente da liberdade ensino sofre com interpretações distorcidas das funções de seus componentes, sobretudo acerca do quão amplo são os âmbitos de proteção das liberdades constitucionais. Não existe discussão diretamente quanto ao papel do direito à educação, este, de maneira geral, existe nos mundos jurídico e social de maneira pacífica e até mesmo em posição preferencial, ou seja, não se discute a contribuição da educação para o desenvolvimento do país, tanto na escala individual como social. Porém, torna-se até complicado compreender 
como é possível defender tão rigorosamente o direito à educação e defender, em igual ou maior intensidade, a imposição de restrições à liberdade de ensino, sendo que esta é um princípio norteador daquele.

A fim de assegurar que, no campo educacional, seria possível levar aos indivíduos as mais variadas ideologias, culturas, informações e valores, o poder constituinte uniu o direito á educação ao complexo constitucional de liberdades, prevendo a liberdade de ensino como guia da educação no país, este pelo menos é o seu fim quando destacada a sua dimensão didática e quando necessariamente vinculada ao princípio do pluralismo de ideias previsto logo após a mesma. Ciente de que o país para o qual estava formulando uma lei geral foi formado a partir da união de culturas e valores provenientes de todas as partes do mundo, o poder constituinte agiu de maneira a tentar evitar que estes elementos formadores nacionais fossem excluídos do processo educacional, aproveitando ainda para impedir que qualquer atitude discriminatória pudesse se tornar parte de tal processo.

No entanto, observa-se hoje, com as cada vez mais comuns tentativas de limitação da liberdade de ensino, sobretudo aquelas fundamentadas em argumentos que defendem supostas violações a outras liberdades constitucionais, como a liberdade de consciência, de expressão e religiosa, que a corrente construída pelo poder constituinte, unindo educação e liberdade, tem sido destruída por atitudes como estas, todas originadas a partir de interpretações distorcidas do texto constitucional, pois não observam os fundamentos da República, não observam os demais direitos e garantias fundamentais e não observam o princípio da unidade da Constituição, ou seja, a forma como deve ser encarada, com todos os seus mandamentos interligados e interdependentes.

Conflitos ou colisões entre direitos fundamentais, conforme já abordado, podem ser solucionados a partir de um processo de ponderação dos interesses, bens e valores em jogo. Tal solução traz à tona o questionamento: não seria mais fácil realizar tal processo antes do nascimento do conflito, não seria mais fácil evitar a imposição de restrições ilegítimas com o uso da proporcionalidade ou razoabilidade antes da criação de um conflito desnecessário e incompatível com a ordem constitucional? A ordem constitucional junto com o bem comum também são elementos analisados durante o processo de ponderação. Por que, então, não considerar tudo isso antes de colocar uma liberdade contra outra?

Entre as consequências negativas da limitação ilegítima da liberdade de ensino, destaca-se o prejuízo do processo de formação da personalidade e consciência humanas e os consequentes golpes causados na manutenção da dignidade humana e do Estado democrático. 
Limitar a exposição aos atores do processo educacional de tudo aquilo que é diferente, mas que também faz parte da sociedade, ceifa o desenvolvimento do pensamento próprio e do senso crítico próprio, tornando mais comum a apropriação por tais atores de consciências herdadas ou moduladas a partir de pensamentos discriminatórios e em nada compatíveis com os valores constitucionais.

É importante destacar que a liberdade de ensino não significa a imposição forçada de determinados ideias, mas sim a exposição dos mais variados ideais, possibilitando a formação autônoma da consciência humana, o que desagua no exercício mais puro da liberdade de consciência. É inaceitável que o processo educacional seja deturpado de forma a servir como ferramenta para a imposição de valores e pensamentos filosóficos e políticos específicos, sobretudo aqueles de caráter discriminatório, mas proibir e condenar a simples exposição do que é diferente constitui medida nada razoável. Trata-se de verdadeiras tentativas de legitimação de comportamentos discriminatórios, que utilizando de má-fé, se escondem atrás do âmbito de proteção de outras liberdades constitucionais, posicionando-as contra a liberdade de ensino.

Como é possível que a formação da consciência humana se dê de forma completa sem que o indivíduo dono de tal consciência tenha sido apresentado à realidade do mundo, ou ao menos de sua sociedade? Como é possível que um pensamento seja expresso tão vigorosamente sem que o seu locutor tenha sido apresentado aos pensamentos contrários ao seu de forma a conferir-lhe a certeza acerca do que está defendendo? Como é possível acabar com conflitos religiosos sem disseminar a aceitação do que é diferente, mas defendendo que a simples exposição do que é diferente já é o suficiente para caracterizar uma violação e demandar atitudes discriminatórias?

Estas perguntas evidenciam a relevância da corrente da liberdade de ensino e o quão é necessário o combate à imposição de restrições a tal princípio quando criadas não para defender acertadamente outras liberdades constitucionais, mas para legitimar comportamentos discriminatórios. A simples obediência dos preceitos que já existem no texto constitucional já seria o suficiente para acabar com estes conflitos desnecessários entre liberdades, já seria o bastante para evitar a distorção do texto constitucional e abolir os abalos às eficácias jurídica e social da corrente que une o direito à educação ao complexo constitucional de liberdades em prol da construção de uma sociedade melhor. 


\section{REFERÊNCIAS}

ALEXY, Robert. Teoria dos Direitos Fundamentais. Tradução: Virgílio Afonso da Silva. 2. ed. São Paulo: Malheiros, 2015.

BADR, Eid. Curso de Direito Educacional: O Ensino Superior Brasileiro. 1. ed. Curitiba: CRV, 2011.

BRASIL. Constituição da República Federativa do Brasil. Brasília: Senado Federal, 1988.

CASTRO, Carlos Roberto Siqueira. A Constituição Aberta e os Direitos Fundamentais: Ensaios sobre o constitucionalismo pós-moderno e comunitário. Rio de Janeiro: Forense, 2010.

CHAVES, Pablo Bonilla. Uma leitura do papel da educação à luz da Constituição Brasileira de 1988: O processo educativo como elemento propulsor da cidadania e da sociedade. 1. ed. Porto Alegre: Núria Fabris, 2010.

DUQUE, Marcelo Schenk. Curso de Direitos Fundamentais: Teoria e Prática. São Paulo: Revista dos Tribunais, 2014.

LENZA, Pedro. Direito Constitucional Esquematizado. 18. ed. São Paulo: Saraiva, 2014.

MALISKA, Marcos Augusto. Comentário ao artigo 206. In: CANOTILHO, J. J. Gomes; MENDES, Gilmar Ferreira; SARLET, Ingo Wolfgang; STRECK, Lenio Luiz. (Coords.). Comentários à Constituição do Brasil. São Paulo: Saraiva/Almedina, 2013.

MARTINS, Flavia Bahia. Direito Constitucional. 3. ed. Niterói: Impetus, 2013.

MENDES, Gilmar Ferreira; BRANCO, Paulo Gustavo Gonet. Curso de Direito Constitucional. 9. ed. São Paulo: Saraiva, 2014.

MENDES, Gilmar Ferreira; COELHO, Inocêncio Mártires; BRANCO, Paulo Gustavo Gonet. Hermenêutica Constitucional e Direitos Fundamentais. 1. ed. Brasília: Brasília Jurídica, 2000.

MOTTA, Elias de Oliveira. Direito Educacional e Educação no Século XXI: com comentários à nova Lei de Diretrizes e Bases da Educação Nacional. Brasília: UNESCO, 1997.

NOVELINO, Marcelo. Direito Constitucional. 6. ed. Rio de Janeiro: Forense; São Paulo: Método, 2012.

PAIVA, Regina Garcia de. Direito Educacional: Do Fato para o Direito. In: TRINDADE, André. (Coord.). Direito Educacional sob uma ótica sistêmica. 1. ed. Curitiba: Juruá, 2010.

SARLET, Ingo Wolfgang; MARINONI, Luiz Guilherme; MITIDIERO, Daniel. Curso de Direito Constitucional. 2. ed. São Paulo: Revista dos Tribunais, 2013. 
SARMENTO, Daniel. Comentário ao artigo 5. ${ }^{\circ}$, IV. In: CANOTILHO, J. J. Gomes; MENDES, Gilmar Ferreira; SARLET, Ingo Wolfgang; STRECK, Lenio Luiz. (Coords.). Comentários à Constituição do Brasil. São Paulo: Saraiva/Almedina, 2013.

SHIRAI, Masako. Direito à Educação: Condução para a Esfera Pública. In: GONÇALVES JUNIOR, Jerson Carneiro; BETTINI, Lucia Elena Polleti; MOREIRA, Eduardo Ribeiro. (Org.). Hermenêutica Constitucional: Homenagem aos 22 anos do Grupo de Estudo Maria Garcia. 1. ed. Florianópolis: Conceito Editorial, 2010.

SILVA, Alexandre Assunção e. Liberdade de Expressão e Crimes de Opinião. 1. ed. São Paulo: Atlas, 2012.

SILVA, José Afonso da. Comentário Contextual à Constituição. 9. ed. São Paulo: Malheiros, 2014.

SILVA, José Afonso da. Curso de Direito Constitucional Positivo. 36. ed. São Paulo: Malheiros, 2013.

TRINDADE, André. Direito Educacional e Direitos Fundamentais: Uma Relação Real. In: TRINDADE, André. (Coord.). Direito Educacional sob uma ótica sistêmica. 1. ed. Curitiba: Juruá, 2010.

WEINGARTNER NETO, Jayme. Comentário ao artigo 5. ${ }^{\circ}$, VI, VII e VIII. In: CANOTILHO, J. J. Gomes; MENDES, Gilmar Ferreira; SARLET, Ingo Wolfgang; STRECK, Lenio Luiz. (Coords.). Comentários à Constituição do Brasil. São Paulo: Saraiva/Almedina, 2013. 